\title{
Biology of inflammation in Crohn's disease: Mechanisms of action of anti-TNF- therapy
}

\author{
Stephan R Targan MD
}

Targan SR. Biology of inflammation in Crohn's disease: Mechanisms of action of anti-TNF- $\alpha$ therapy. Can J Gastroenterol 2000;14(Suppl C):13C-16C. Several recent trials of intravenously administered antitumour necrosis factor-alpha (TNF- ) monoclonal antibody have shown dramatic responses among patients with Crohn's disease. These results indicate a primary role for TNF- in the mediation of altered mucosal immune function in this disease. Clinical responses in patients treated with a single infusion of anti-TNF- persisted for as long as one year. The prolonged period of clinical benefit shows that the effect of short term TNF- elimination remains long after the monoclonal antibody has cleared the body. Corresponding in vitro investigation has shown that $\mathrm{T}$ helper 1 (Th1) -mediated cytokine production of interferon-gamma is downregulated in the involved mucosa to a level consistent with that seen in uninflamed mucosa. These results suggest that TNF- -specific augmentation of mucosal Th1 function is the process that is altered by removal of TNF- and that produces such persistent responses. Understanding how TNF- modulates mucosal Th1 function may lead to the definition of a key feature of Crohn's disease pathogenesis.

Key Words: Crohn's disease; Inflammation; Mechanisms of action; Tumour necrosis factor-alpha

\section{Biologie de l'inflammation dans la maladie de Crohn : mécanismes d'action du traitement à l'anti-TNF- $\alpha$}

RÉSUMÉ : Des perfusions d'anticorps monoclonal anti-facteur de nécrose tumorale alpha (TNF- ), administrées dans le cadre de plusieurs essais récents, ont provoqué des réactions remarquables chez des patients atteints de la maladie de Crohn. Les résultats indiquent que le TNF- joue un rôle important dans la médiation de la fonction immunitaire des muqueuses touchées. On a observé des réactions cliniques d'une durée d'un an après une seule perfusion d'anti-TNF- . La durée prolongée du bienfait clinique est le signe que l'effet de l'élimination à court terme du TNFpersiste bien au-delà de l'excrétion de l'anticorps monoclonal. Une recherche parallèle menée in vitro a montré que la production d'interféron gamma médiée par les lymphocytes $\mathrm{T} 1$ auxiliaires (Th 1 ) dans la muqueuse atteinte a été ramenée à une production comparable à celle observée dans les muqueuses saines. Les résultats semblent indiquer que l'augmentation spécifique de la fonction des Th 1 dans la muqueuse par le TNF- est le processus qui est modifié par l'élimination du TNF-, d'où réactions persistantes. Le fait de comprendre le mécanisme par lequel le TNFmodule la fonction des Th 1 dans la muqueuse pourrait mener à la caractérisation d'un élément clé de la pathogenèse de la maladie de Crohn.
$\mathrm{O}$ ver the past three years, progress toward understanding the pathogenesis of Crohn's disease (CD) has accelerated as a result of scientific achievement on two fronts. First, over 30 different animal models of mucosal inflammation, created by genetic or cellular manipulations, have focused attention on the inflammatory mediators that are central to the development of ileitis and colitis. Second, the availability of inhibitors of specific inflammatory molecules, particularly antitumour necrosis factor-alpha (TNF- ), has allowed the role of such molecules in human disease to be ascertained.

The central abnormality in human CD and most animal models is an imbalance of proinflammatory and antiinflammatory mediators in the mucosa. An enhanced $\mathrm{T}$ helper (Th) (Th1, interferon-gamma [IFN-] and/or TNF- ) response, and/or lack of a counterregulatory $\mathrm{T}$ regulatory $(\operatorname{Tr})(\operatorname{Tr} 1$, interleukin [IL] -10) or Th (Th3, trans-

Cedars-Sinai Medical Center, Los Angeles, California, USA

Correspondence and reprints: Dr Stephan R Targan, Director, Cedars-Sinai Division of Gastroenterology and Inflammatory Bowel Disease Center, 8700 Beverly Boulevard, Suite D4063, Los Angeles, California, USA 90048. Telephone 310-423-7723, fax 310-423-0224,

e-mail stephan.targan@cshs.org 
forming growth factor-beta [TGF- ]) response results in chronic mucosal inflammation in these animal models. In the mucosa of many patients with active $\mathrm{CD}$, the cytokines critical for generation of a Th1 response (IFN- and TNF- , IL-18 and IL-12) are increased.

TNF- , a molecule produced by both macrophages and $\mathrm{T}$ cells, exists in a transmembrane and a soluble trimeric form. Antibodies to TNF- may inhibit this action by blocking its biological activity or by inducing the cells that express TNF- as part of the apoptotic process. The importance of TNF- in CD-like inflammation has been directly demonstrated in the TNF- 'knock-in' model. The model, which is engineered to produce high and persistent levels of TNF- , reproduces a transmural inflammatory ileal disease similar to $\mathrm{CD}$. This model requires $\mathrm{T}$ cells for inflammation; thus, the interplay between TNF- and T cells is critical for disease expression. In the majority of mouse models, antibodies to TNF- either prevent or attenuate colitis. This response is paralleled by a downmodulation of Th1 cytokine production.

Blockage of TNF- has profound effects in the mucosa. These include downregulation of $\mathrm{T}$ cells capable of producing Th1 cytokines, expression of several adhesion molecules and expression of $\mathrm{T}$ cell-activating ligands and receptors. Results from studies of human CD reflect what has been seen in animal models.

\section{CYTOKINES AND MUCOSAL INFLAMMATION}

Normal mucosa is in a state of perpetually controlled or orchestrated inflammation, characterized by an intricate balance of immune mediators in response to various antigenic stimuli in a genetically regulated environment (1). Failure of normal regulatory mechanisms, and perhaps persistent antigen presence, may result in a lack of downregulation of inflammation. Inflammatory bowel disease (IBD) pathogenesis may be the result of an abnormal immune response to a common antigen or may represent a failure to suppress the normal immune response.

Macrophages and Th1 cells help to promote inflammation by producing proinflammatory cytokines, including IL-1, IL-6, IL-8, IL-12, TNF- and IFN- , all of which incite inflammation $(2,3)$. Production of Th1-type cytokines is stimulated by TNF- $(4,5)$. Macrophages and Th2 cells produce anti-inflammatory cytokines, which include IL-4, IL-10, TGF- and IL-1 receptor antagonist.

\section{THE 'IMMUNOSTAT'}

The therapeutic effect of cytokines in the regulation of inflammation may be to reset the immune response, the immunostat, so that secretion of Th1 cytokines is balanced against that of $\operatorname{Th} 2, \operatorname{Tr} 1$ or Th3 cytokines. The immunostat properties of cytokines may persist beyond the point where the therapeutic cytokine can be measured (in the case of cytokine therapy) or where its absence can be detected (as with the use of anticytokines). The extended clinical effect of anti-TNF- therapy, long after any antibody can be detected in the patient, may be explained by the fact that the level of IFN- production in the intestine (as opposed to the periphery) is dependent upon the presence of TNF- and suggests a mechanism by which anti-TNF- may reset the mucosal immunostat.

\section{THE ROLE OF TNF- $\alpha$ IN THE PATHOGENESIS OF MUCOSAL INFLAMMATION AND IBD}

Several studies have detected increased TNF- protein and mRNA levels in mucosal biopsies from patients with $C D$ $(6,7)$; others have not $(8,9)$. Several recent trials of intravenously administered anti-TNF- monoclonal antibody therapy have shown dramatic responses in $\operatorname{CD}(10,11)$. These results show a primary role for TNF- in the mediation of altered mucosal immune function and inflammation in CD. The extended duration of clinical responses (up to one year) in a small proportion of patients treated with a single infusion of anti-TNF- may be due to one or more mechanisms, including the elimination of soluble TNF- , blockage of transmembrane TNF- function or the elimination of a cell or cells expressing transmembrane TNF- . Thus, the removal of TNF- for a relatively short period of time by anti-TNF- antibodies results in a prolonged and sustained downregulation of the hyperactive inflammatory state. Anti-TNF- therapy in the treatment of human CD retains its effect long after elimination of the antibodies. This finding suggests that the most important effect of blocking TNF- is a protracted adjustment of the level of immune response within the mucosa.

The mechanism by which TNF- regulates inflammation in the gut of patients with CD is likely complex and multifactorial. To determine this mechanism, a series of in vitro experiments were performed using specimens from patients participating in clinical trials of anti-TNF- $(12,13)$. The role of TNF- in induction of the hyperactive T-cell state known to be present in CD mucosa was evaluated in $10 \mathrm{pa}-$ tients with steroid-resistant disease (13). In this small study, nine of 10 patients were evaluated at baseline and four weeks after administration of a single infusion of anti-TNFmonoclonal antibody. Nine attained clinical and endoscopic remission, and six of the nine patients maintained remission for eight weeks. The leukocyte chemoattractant RANTES, derived from activated $\mathrm{T}$ cells, was detectable in biopsy specimens taken at baseline, but not in samples taken four weeks after the infusion (12). These results demonstrate that anti-TNF- downregulates the number, or activation state, of mucosal $\mathrm{T}$ cells and suggest that TNF- is critical for the maintenance of the hyperactive $\mathrm{T}$-cell state in CD.

The lengthy duration of response to one infusion of antiTNF- monoclonal antibody was examined in another series of in vitro studies, performed in conjunction with an open-label trial. In patients responsive to treatment with anti-TNF- , there was sequential downregulation of TNFand IFN- production in the mucosa. Th1 T cells were not eliminated; rather, their function was reduced in inflamed mucosa to a level comparable with that seen in noninflamed mucosa. This reduction in Th1 cytokines suggests 
that TNF- -augmented Th1 function, not simply Th1 function, was critical for disease pathogenesis. This decrease in Th1 cell function persisted throughout the duration of the clinical response (13).

Both studies demonstrated that anti-TNF- therapy has a profound effect on the level and function of activated $T$ cells within the mucosa, and confirmed that both a hyperactive T-cell state and enhancement of Th1 cytokine are central to pathogenesis. The presence of soluble or transmembrane TNF- in the mucosa plays a critical role in the maintenance of this heightened and shifted $\mathrm{T}$-cell response. Finally, the data suggest that the prolonged clinical benefit seen with anti-TNF- therapy may be affected through partial reversal of these altered processes.

Monocytes, macrophages and $\mathrm{T}$ cells are the major producers of TNF- (14). Increased TNF- levels are associated with sequential increases in IL-1, IL-6 and IL-8 (15), and vice versa. This correlative response suggests that TNFfunctions early in the inflammatory cascade and that enhancement of Th1 cytokines is central.

TNF- appears to have an important role in regulation of the inflammation that characterizes $C D(13,16-21)$. Patients with IBD have greater numbers of mucosal TNF- -producing cells (21-23) and higher levels of mucosal TNF(17-21) than healthy individuals.

\section{EXPERIMENTAL MODELS OF CYTOKINE REGULATION OF MUCOSAL INFLAMMATION}

Several rodent models of mucosal inflammation have been refined using cellular and molecular manipulations of mucosal T-cell regulation. Most of these animals develop colitis marked by overproduction of Th1-type cytokines, particularly IFN- and TNF- . More recently, a rodent model of mucosal inflammation characterized by increased numbers and activity of Th2 cytokine production (IL-4) has been generated by deletion of the $\mathrm{T}$-cell receptor-alpha gene in mice (23).

In Th1-type models, inhibition of the specific cytokines responsible for initiation of a T-cell response (eg, anti-IFN- , anti-TNF- or anti-IL-12) either eliminates or ameliorates the development of mucosal inflammation. Treatment of these animals with the Th1 downregulatory cytokine, IL-10 (Tr1), with or without stimulation of local TGF- (Th3) production, also inhibited inflammatory responses (24). The roles of any one cytokine, a combination of cytokines and anticytokines, developed to counteract their effects in human disease, can only be determined by clinical trials in populations of patients with IBD.

Several studies in rodent models have defined TNF- as a critical factor in mucosal inflammation. The first model to indicate such a role for TNF- was the CD4+CD45RB high $\mathrm{T}$-cell transfer to congenic or semisyngeneic mice with severe combined immunodeficiency disease. The resulting inflammation was more severe in the large intestine, and pathogenesis was characterized by the overproduction of Th1-type cytokines (IFN- ) $(25,26)$. This model system is similar to at least two-thirds of CD patients in whom cyto- kine secretion undergoes a shift to a Th1 phenotype $(25,26)$. Production and synthesis of Th1 cytokines appear to be important for disease pathogenesis in this model, because treatment with recombinant IL-10, anti-IFN- or anti-TNFmonoclonal antibodies (inhibitors of Th1 development and function) attenuates or completely eliminates the colitis (24).

Using a mouse model of trinitrobenzene sulphonic acid (TNBS) -induced colitis, several studies have highlighted the importance of TNF- in mucosal inflammation. In this model, the successful elimination of disease with administration of anti-IFN- , anti-TNF- or anti-IL-12 monoclonal antibodies has proved that the colitis is Th1-dependent $(25-27)$. In another investigation, mice with chronic colitis were treated by intraperitoneal injection of antibodies to TNF- and showed a marked improvement of both clinical and histopathological signs of disease (25-27).

The predominant role of TNF- in colitis was further demonstrated by the finding that much more severe, indeed lethal, disease could be induced in TNF- transgenic mice with TNBS-induced colitis (27). No significant colitis could be induced in mice in whom the TNF- gene had been inactivated by homogeneous recombination. Complementation of TNF- function in $\mathrm{TNF}^{-1-}$ mice by expression of a mouse TNF- transgene was sufficient to reverse this effect (25). These studies, therefore, have provided direct evidence of a predominant role of TNF- in mouse models of Th1mediated chronic intestinal inflammation. Other studies using the TNBS model have demonstrated a dominant pathogenic role of Th1 T-cell-derived cytokines, suggesting that TNF- may regulate inflammation by modulation of IFNproduction (25-27). Determination of the mechanism by which TNF- regulates Th1 cytokines may lend great insight into a component of the critical regulatory processes that initiate and perpetuate chronic intestinal inflammation.

\section{REFERENCES}

1. Stenson WF. Inflammatory bowel disease. In: Yamada T, ed. Textbook of Gastroenterology, 2nd edn. Philadelphia: JB Lippincott Company, 1995:1748-806.

2. Mosmann TR, Coffman RL. TH1 and TH2 cells: different patterns of lymphokine secretion lead to different functional properties. Annu Rev Immunol 1989;7:145-73.

3. Powrie F, Coffman RL. Cytokine regulation of T-cell function: potential for therapeutic intervention. Immunol Today 1993;14:270-4.

4. Flesch IE, Hess JH, Huang S, et al. Early interleukin 12 production by macrophages in response to mycobacterial infection depends on interferon gamma and tumor necrosis factor alpha. J Exp Med 1995;181:1615-21.

5. Hernandez-Pando R, Rook GA. The role of TNF-alpha in T-cell-mediated inflammation depends on the Th1/Th2 cytokine balance. Immunology 1994;82:591-5.

6. MacDonald TT, Hutchings P, Choy MY, Murch S, Cooke A. Tumor necrosis factor-alpha and interferon-gamma production measured at the single cell level in normal and inflamed human intestine. Clin Exp Immunol 1990;81:301-5.

7. Murch SH, Braegger CP, Walker-Smith JA, MacDonald TT. Location of tumor necrosis factor alpha by immunohistochemistry in chronic inflammatory bowel disease. Gut 1993;34:1705-9.

8. Isaacs KL, Sartor RB, Haskill S. Cytokine messenger RNA profiles in inflammatory bowel disease mucosa detected by polymerase chain reaction amplification. Gastroenterology 1992;103:1587-95.

9. Stevens C, Walz G, Singaram C, et al. Tumor necrosis factor-alpha, interleukin-1 beta, and interleukin-6 expression in inflammatory bowel disease. Dig Dis Sci 1992;37:818-26. 
10. van Dulleman HM, van Deventer SJ, Hommes DW, et al. Treatment of Crohn's disease with anti-tumor necrosis factor chimeric monoclonal antibody (cA2). Gastroenterology 1995;109:129-35.

11. Targan SR, Hanauer SB, van Deventer SJ, et al. A short-term study of chimeric monoclonal antibody cA2 to tumor necrosis factor- for Crohn's disease. Crohn's Disease cA2 Study Group. N Engl J Med 1997;337:1029-35.

12. Radema SA, van Dullemen HM, Mevissen M, Tytgat GNJ, van Deventer SJH. Anti-tumor necrosis factor therapy decreases production of the chemokines rantes, MCP, and MIP-2 in patients with Crohn's disease. Gastroenterology 1995;108:A898. (Abst)

13. Plevy SE, Landers CJ, Prehn J, et al. A role for TNF-alpha and mucosal T helper-1 cytokines in the pathogenesis of Crohn's disease. J Immunol 1997;159:6276-82.

14. Vassalli P. The pathophysiology of tumor necrosis factors. Annu Rev Immunol 1992;10:411-52.

15. Feldmann M, Elliott MJ, Woody JN, Maini RN. Anti-tumor necrosis factor-alpha therapy of rheumatoid arthritis. Adv Immunol 1997;64:283-350.

16. Murch SH, Braegger CP, Walker-Smith JA, MacDonald TT. Location of tumor necrosis factor-alpha by immunohistochemistry in chronic inflammatory bowel disease. Gut 1993;34:1705-9.

17. MacDonald TT, Hutchings P, Choy MY, Murch S, Cooke A. Tumor necrosis factor-alpha and interferon-gamma production measured at the single cell level in normal and inflamed human intestine. Clin Exp Immunol 1990;81:301-5.

18. Reimund JM, Wittersheim C, Dumont S, et al. Mucosal inflammatory cytokine production by intestinal biopsies in patients with ulcerative colitis and Crohn's disease. J Clin Immunol 1996;16:144-50.

19. Reimund JM, Wittersheim C, Dumont S, et al. Increased production of tumor necrosis factor-alpha, interleukin-1 beta, and interleukin-6 by morphologically normal intestinal biopsies from patients with Crohn's disease. Gut 1996;39:684-9.

20. Reinecker HC, Steffen M, Witthoeft T, et al. Enhanced secretion of tumour necrosis factor-alpha, IL-6, and IL-1 beta by isolated lamina propria mononuclear cells from patients with ulcerative colitis and Crohn's disease. Clin Exp Immunol 1993;94:174-81.

21. Breese EJ, Michie CA, Nicholls SW, et al. Tumor necrosis factor-alpha producing cells in the intestinal mucosa of children with inflammatory bowel disease. Gastroenterology 1994;106:1455-66.

22. Braegger CP, Nicholls S, Murch SH, Stephens S, MacDonald TT. Tumor necrosis factor alpha in stool as a marker of intestinal inflammation. Lancet 1992;339:89-91.

23. Mizoguchi E, Mizoguchi A, Bhan AK. Role of cytokines in the early stages of chronic colitis in TCR alpha-mutant mice. Lab Invest 1997;76:385-97.

24. Powrie F, Correa-Oliviera R, Mauze S, Coffman RL. Regulatory interactions between CD45RB high and CD45RB ${ }^{\text {low }} \mathrm{CD} 4+$ cells are important for the balance between protective and pathogenic cell mediated immunity. J Exp Med 1994;179:589-600.

25. Powrie F, Leach MW, Mauze S, Manen S, Caddle LB, Coffman RL. Inhibition of Th1 responses prevents inflammatory bowel disease in scid mice reconstituted with CD45RB high CD4+ T cells. Immunity 1994;179:589-600.

26. Mizoguchi A, Mizoguchi E, Bhan AK. The critical role of interleukin 4 but not interferon gamma in the pathogenesis of colitis in T-cell receptor alpha mutant mice. Gastroenterology 1999;116:320-6.

27. Strober W, Kelsall B, Fuss I, et al. Reciprocal IFN-gamma and TGF-beta responses regulate the occurrence of mucosal inflammation. Immunol Today 1997;18:61-4. 


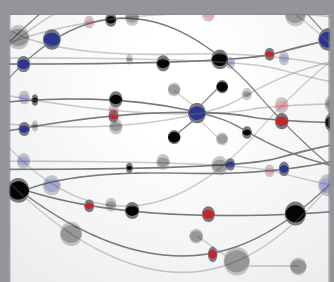

The Scientific World Journal
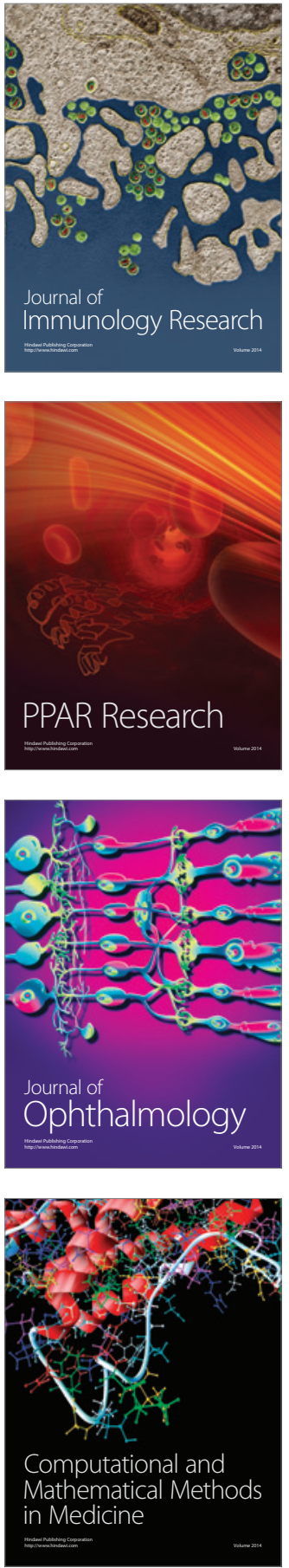

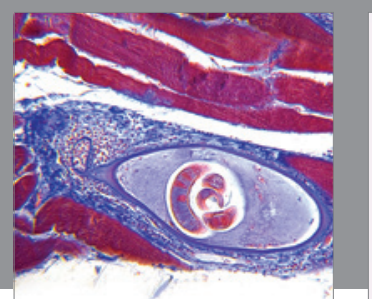

Gastroenterology Research and Practice

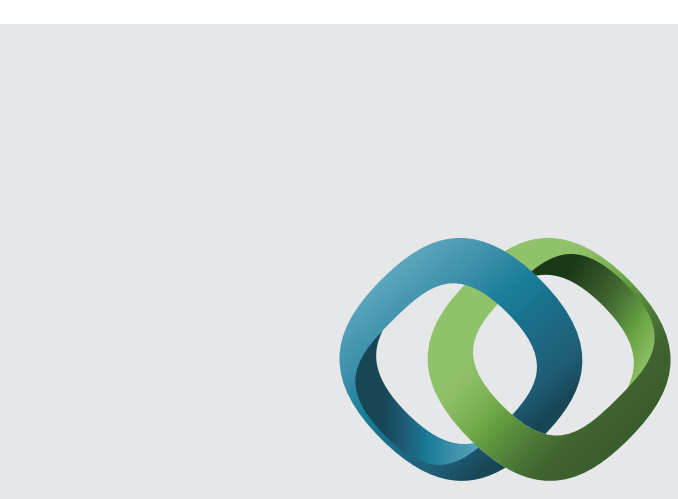

\section{Hindawi}

Submit your manuscripts at

http://www.hindawi.com
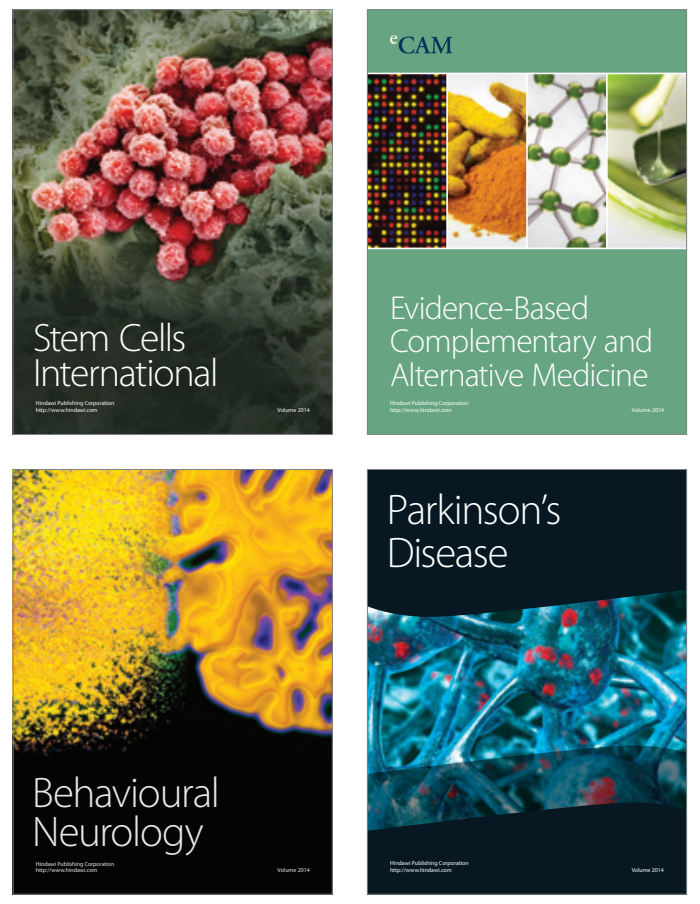
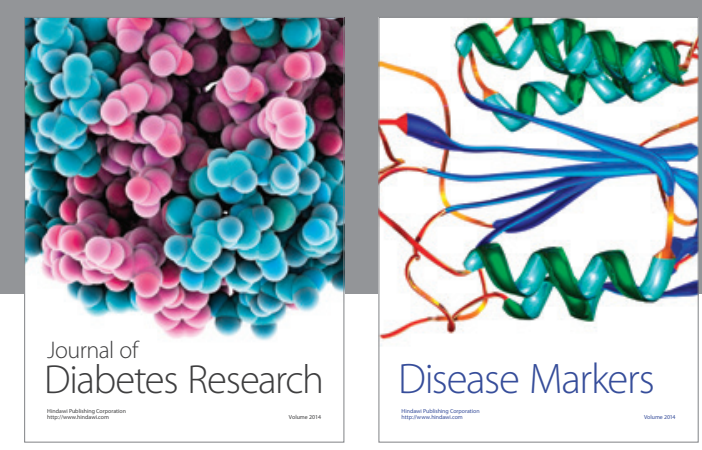

Disease Markers
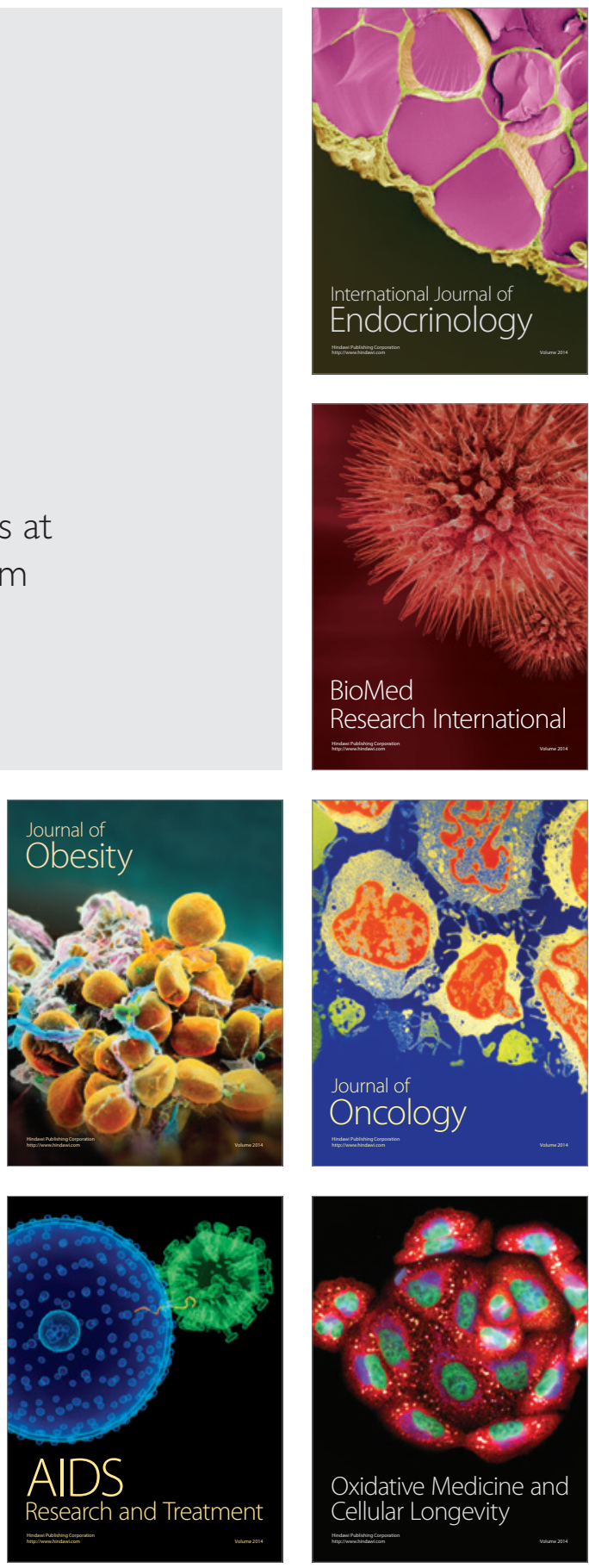